\title{
Serological Diagnosis of Feline Tegumentary Leishmaniasis by Indirect Immunofluorescence (IFI) and Enzyme-Linked Immunosorbent Assay (ELISA) in an Endemic Area in Brazil
}

\author{
Fabiano Borges Figueiredo', Lílian Dias Nascimento ${ }^{2}$, Tassia Cristina Bello de Vasconcelos ${ }^{3}$, \\ Maria de Fátima Madeira ${ }^{4}$, Eliame Mouta Confort ${ }^{4}$ \& Tânia Maria Valente Pacheco Schubach ${ }^{1}$
}

\begin{abstract}
Background: American tegumentary leishmaniasis (ATL) is a serious public health problem, and the participation of domestic cats in its epidemiological process has not yet been fully elucidated. Therefore, the standardization of monitoring methodologies of cat populations becomes important for the generation of information on the disease. In Brazil, ATL presents a wide geographical distribution, being Leishmania (Viannia) braziliensis its etiologic agent of ATL in Rio de Janeiro. The main objective of the present study was investigate the presence of specific anti-Leishmania (Viannia) braziliensis Immunoglobulin $\mathrm{G}(\mathrm{IgG})$ in 34 cats from an ATL endemic area in this municipality.

Materials, Methods \& Results: Sera from three cats from the study area naturally infected with Leishmania (Viannia) braziliensis were used as positive control. Analyses were performed with antigen preparations using indirect immunofluorescence (IFI) and enzyme-linked immunosorbent assay (ELISA). We found prevalence rates of 20.6\% (7/34) in the IFI and $14.7 \%(5 / 34)$ in the ELISA. Specificity was $87.1 \%$ for the IFI and $93.5 \%$ for the ELISA, and both tests presented sensitivity of $100 \%$. Concordance between the used tests was assessed as moderate.

Discussion: By conducting a feline serological survey in an endemic area for ATL we provide information on the involvement of this species in such epidemiological process. In this context, the participation of the cat in cycles of leishmaniases has been highlighted by several authors; infection of the phlebotomine by parasites originated from this vertebrate host can already be demonstrated by xenodiagnosis and several cases of feline infection have been reported in endemic regions of several countries such as Brazil, Spain, France, Portugal, Greece, Iran, Israel and Italy. Therefore, the standardization of diagnostic techniques that support the screening and monitoring of such populations becomes of utmost importance. In fact, the use of the IFI and ELISA serological techniques, showing sensitivity and NPV of $100 \%$, confirm the use of such tools in epidemiological surveys for the detection of anti-L. (V.) braziliensis antibodies in domestic cats, and these methodologies are frequently employed in canine surveys showing good results. The serological titers found in this study for Leishmania $(V$.) braziliensis are similar to those of studies carried out with cats in endemic areas of visceral leishmaniasis in Spain. This similarity shows that the titers can be high even when $L$. (V.). braziliensis is the etiological agent. It is worth mentioning that these values are significant when compared with those of canine studies carried out in ATL endemic regions. Ultimately, the sample refers to an ATL endemic region located in Brazil, one of the countries with the highest endemicity levels of cutaneous leishmaniasis in the world and, therefore, an important area for the implementation and evaluation of diagnostic techniques for the generation of data on the disease and its possible hosts. Thus, the present study provides information on the occurrence of ATL by Leishmania $(V$.) braziliensis in domestic cats; demonstrates that the methodologies employed were favorable to the use of such techniques as tools in epidemiological surveys for the diagnosis of feline tegumentary leishmaniasis; and paves the way for further studies on the subject.
\end{abstract}

Keywords: Leishmania (Viannia) braziliensis, domestic cat, serological diagnosis. Cruz (FIOCRUZ), Rio de Janeiro, RJ, Brazil. ${ }^{2}$ Seção de Células e Vírus, Departamento de Reativos para Diagnóstico, Instituto de Tecnologia em Imunobiológicos, FIOCRUZ, Rio de Janeiro. ${ }^{3}$ Pós-graduação em Medicina Veterinária, Universidade Federal Fluminense (UFF), Niterói, RJ. ${ }^{4}$ Laboratório de Vigilância em Leishmanioses, Instituto Nacional de Infectologia Evandro Chagas, FIOCRUZ, Rio de Janeiro. CORRESPONDENCE: T.C.B. Vasconcelos [tassia.vasconcelos@gmail.com - Tel.: +55 (21) 3865-9536]. Pós-graduação em Medicina Veterinária, Universidade Federal Fluminense (UFF). Rua Miguel de Frias n. 9. Bairro Icaraí. CEP 24220-900 Niterói, RJ, Brazil. 


\section{INTRODUCTION}

American tegumentary leishmaniasis (ATL) is a serious public health problem that can cause destructive, occasionally disabling, deformities. In Brazil, ATL presents a wide geographical distribution [15], being Leishmania (Viannia) braziliensis is the etiologic agent of ATL in the municipality of Rio de Janeiro [5]. In this context, it is worth mentioning the presence of domestic hosts such as cats, which may act as reservoirs and amplifiers of cycles installed in the peridomicile $[13,25]$.

The first case of feline leishmaniasis (FL) was described in Algeria [38]. Since then, authors have been notifying both the cutaneous and visceral forms, in felines from around the world [3,6,9,17,19,31,33,35].

In Brazil, the first report of FL occurred in 1939 [26]. Later, other cases were reported $[9,32]$ with $L$. (Viannia) and Leishmania (Leishmania) amazonensis. In São Paulo state, it was suggested that the cat could be part of the transmission cycle as a leishmaniasis reservoir in endemic areas [36] and in Rio de Janeiro state, the presence of domestic cats infected with $L$. (V.) braziliensis is concurrently with canine and human infections [14,37].

In this context, this study aimed to evaluate the detection of specific IgG in samples of domestic cats using IFI and ELISA reactions with antigen preparations of Leishmania (V.) braziliensis. Based on the use of such methodology in an endemic area for ATL, we sought to demonstrate the feasibility of these techniques for the diagnosis and monitoring of cat populations susceptible to cutaneous leishmaniasis.

\section{MATERIALS AND METHODS}

\section{Study design}

The study consists of the serological evaluation of 34 domestic cats (Felis catus) from an ATL endemic area in the municipality of Rio de Janeiro using the IFI and ELISA methods with Leishmania (Viannia) braziliensis antigen preparations.

Three cats from the study area naturally infected with Leishmania (V.) braziliensis, diagnosed by culture isolation and characterization of isoenzymes, were used as positive control. Such isolation and characterization procedures were performed for all animals in the study which presented skin lesions, and co-infection with the viruses of Feline Immuno- deficiency (FIV) and Feline Leukemia (FeLV) were also assessed by means of detection of antigens and antibodies, respectively (SNAP ${ }^{\circledR}$ FIV Antibody/FeLV Antigen Combo Test).

Parasitological culture and isoenzymatic characterization

Animals presenting skin lesions were submitted to parasitological diagnosis. Fragments were collected from the edge of the lesions using a 3-mm punch. This procedure was carried out after the animals were sedated, by intramuscular injection, with ketamine hydrochloride at $10 \%(10 \mathrm{mg} / \mathrm{kg})$ associated with acepromazine at $1 \%(0.2 \mathrm{mg} / \mathrm{kg})$ and local anesthesia with lidocaine hydrochloride at $2 \%$. The fragments were stored in saline solution containing 1,200 UI of penicillin, 1,000 ug of streptomycin, and $100 \mathrm{ug}$ of 5 ' fluorocytosine per milliliter; after $24 \mathrm{~h}$, they were seeded in NNN (Novy, MacNeal, Nicolle)/ Schneider biphasic culture medium supplemented with $10 \%$ fetal bovine serum. The vials were incubated at room temperature $\left(26-28^{\circ} \mathrm{C}\right)$ and examined weekly. The isolates were characterized by electrophoresis of enzymes using a previously established protocol [7].

ELISA

The assays were performed according to the procedures previous described [29]. Polystyrene 96well plates (Nunc immuno Maxisorp 96-well plates) ${ }^{1}$ were sensitized with $100 \mathrm{uL}$ of the total Leishmania $(V$.$) braziliensis antigen partially soluble at a concen-$ tration of $2.5 \mu \mathrm{g} / \mathrm{mL}$ diluted in carbonate-bicarbonate $\mathrm{pH} 9.6$ buffer solution; they were subsequently incubated overnight (for $18 \mathrm{~h}$ ) at $4^{\circ} \mathrm{C}$. After four washes with PBS pH 7.2 with $0.05 \%$ of Tween 20 (PBS-T), $100 \mu \mathrm{L}$ of the serum samples diluted at 1:40 in PBS-T containing $1 \%$ skim milk (PBS-TL) were added to each well; incubation for 45 minutes at $37^{\circ} \mathrm{C}$ in a humid chamber was then conducted.

After four new washes, $100 \mu \mathrm{L}$ of Goat anti-cat IgG Fc conjugated with horseradish peroxidase (HRP A20-117P) $)^{2}$ diluted 1:40,000 in PBS-TL were added. After $45 \mathrm{~min}$ of incubation at $37^{\circ} \mathrm{C}$ in a moist chamber and four new washes, we added $100 \mu \mathrm{L}$ of developing solution, composed by $10 \mathrm{mg}$ of o-phenylenediamine $(\mathrm{OPD}, \mathrm{P} 1526)^{3}$ and $10 \mu \mathrm{L}$ of hydrogen peroxide $\left(\mathrm{H}_{2} \mathrm{O}_{2}\right)$ in $25 \mathrm{~mL}$ of citrate-phosphate buffer solution at $\mathrm{pH}$ 5.0.

The plates were incubated for $15 \mathrm{~min}$ in the dark, and the reaction was interrupted by adding 50 $\mu \mathrm{L}$ of $1 \mathrm{~N} \mathrm{H}_{2} \mathrm{SO}_{4}$ to each well. The optical density of 
the wells was determined in a plate reader using a 492 nm wavelength filter. The cutoff point was established by the average of the negative controls plus twice the standard deviation thereof.

\section{IFI}

Promastigote forms of Leishmania (V.) braziliensis (MHOM/BR/75/M2903) were used as antigen. The slides were covered with $10 \mu \mathrm{L}$ of the antigen and incubated at $37^{\circ} \mathrm{C}$ for $2 \mathrm{~h}$. The sera were diluted as of 1:40 in PBS pH 7.2. After incubation in a humidified chamber at $37^{\circ} \mathrm{C}$ for $30 \mathrm{~min}$, the slides were washed three times for five minutes in PBS and every minute in distilled water. The conjugate (Goat anti-cat IgG $\mathrm{Fc}$ fragment, A20-117F) ${ }^{2}$ was diluted at 1:50 in PBS with 1:25 of Evans blue, and $10 \mu \mathrm{L}$ of this solution was added to each well of the plate. The incubation and wash phases were repeated as previously mentioned. The slides were mounted with buffered glycerin and closed with cover slip for reading in fluorescence microscope. Titers $>$ 1:40 were considered positive [34].

\section{Statistical analysis}

Prevalence, sensitivity, specificity, positive predictive values (PPV) and negative predictive values (NPV) were calculated using the Statistical Package for the Social Science (SPSS), version 16.0. The results of parasitological culture were used as reference standard. Concordance between IFI and ELISA was assessed by the Kappa (k) index, according to the following classification [40]: $\mathrm{k}=0.00$ to 0.10 , virtually absent; $\mathrm{k}=$ 0.11 to 0.40 , weak; $\mathrm{k}=0.41$ to 0.60 , slight; $\mathrm{k}=0.61$ to 0.80 , moderate; and $\mathrm{k}=0.81$ to 1.0 , significant.

\section{RESULTS}

Sera from 34 cats from an ATL endemic area were assessed using IFI and ELISA.

Results showed positivity prevalence of $20.6 \%$ (7/34) in the IFI and $14.7 \%$ (5/34) in the ELISA, and no statistical significance was observed between these results $(P=0.75$, Chi-square test, $\mathrm{CI}=95 \%)$.

Among the 34 animals evaluated, five presented skin lesions compatible with ATL and were submitted to parasitological diagnosis, from which three individuals with positive results regarding isolation of the parasite were obtained.

Sensitivity and NPV were $100 \%$ in both the IFI and the ELISA. Specificity and PPV were $87.1 \%$ and $42.9 \%$ for the IFI and $93.5 \%$ and $60.0 \%$ for the ELISA, respectively. The samples from animals with positive isolation of Leishmania showed, in the IFI reaction, titers equal to or greater than 1:160, while the samples from animals with negative results for the isolation of the parasite showed titers of 1:40 and 1:80. Overall agreement between the IFI and ELISA reactions was $84.1 \%$, presenting co-positivity and co-negativity of $14.7 \%$ and $79.7 \%$, respectively. Although the specificity values obtained with the ELISA technique are higher than those obtained with the IFI technique, this difference is not statistically significant $(P=0.67$, Chisquare test, $\mathrm{IC}=95 \%$ ).

The Kappa index value was 0.80 , which classifies the concordance between IFI and ELISA as moderate [40].

Of the five felines presenting clinical suspicion for the disease, only one did not obtain diagnostic confirmation by any of the techniques applied, both serological and parasitological, so that rate of symptomatic cats was $57.1 \%$ (4/7), based on the most prevalent test. Regarding the search for antigens of FeLV and antibodies for FIV, six animals tested positive for FeLV. However, all individuals with parasitological diagnosis were negative in this test, and only one, an exclusively serum reagent cat, showed detection of such antigens.

\section{DISCUSSION}

By conducting a feline serological survey in an endemic area for ATL we seek to provide information on the involvement of this species in such epidemiological process. In this context, the participation of the cat in cycles of leishmaniases has been highlighted by several authors $[4,20,21,30,36]$; infection of the phlebotomine by parasites originated from this vertebrate host can already be demonstrated by xenodiagnosis $[8,23]$ and several cases of feline infection have been reported in endemic regions of countries such as Brazil [9,37], Spain [17,24] France [31], Portugal [4,21], Greece [10], Iran [11], Israel [30] and Italy [33].

In view of this situation, the standardization of diagnostic techniques that support the screening and monitoring of such populations becomes of utmost importance. In this study, the use of the IFI and ELISA serological techniques, showing sensitivity and NPV of $100 \%$, confirm the use of such tools in epidemiological surveys for the detection of anti-L. (V.) braziliensis antibodies in domestic cats. In fact, these methodologies are frequently employed in canine surveys showing 
good results $[2,28,42]$ and the adequacy of both techniques to felines confirm the previous results [18,34].

The serological titers found in this study for Leishmania $(V$.$) braziliensis are similar to those of$ studies carried out with cats in endemic areas of visceral leishmaniasis in Spain [17,24]. This similarity shows that the titers can be high even when L. (V.). braziliensis is the etiological agent.

Prevalence of the disease in the study area was high when compared to some works [4,41], who obtained a rate of $3.9 \%$ in a cohort of 153 cats using ELISA in the search for infection with L. Infantum, and rates of $2.8 \%$ and $1.9 \%$ in a sample of 316 cats using ELISA and direct agglutination. The same occurred in others works [1,33], with $4.29 \%$ in a group of 233 animals, and with $0.9 \%$ in a sample of 110 felines, both ones carried out using IFI in studies of visceral leishmaniasis.

Our results were also higher than anothers $[10,27,30]$; similar to one [46]; but lower than other [24]. It is worth mentioning that these values are significant when compared with those of canine studies carried out in ATL endemic regions [12,15,39].

With respect to the clinical aspect, the presence of four animals classically symptomatic for ATL, among those with detectable immune response, oppose the high rate of asymptomatic feline leishmaniasis previous described for the visceral form [22]. Nevertheless, such result approximates that other [41], who obtained two symptomatic felines from four serum reagent cats in search for $L$. infantum. As for the non-symptomatic serum reagent animals, they evince the contact with the parasite without evolution of the clinical disease process. In fact, it is supported the hypothesis that, in infections with $L$. infantum, the immune response in cats is effective enough to control the infection and promote resistance to certain animals when there are no concomitant immunosuppressive events [43].
In this context, despite the existence of an indication that coinfection between FeLV and Leishmania spp. may favor the pathological process by the protozoan [17] the detection of viral antigens in only one animal serum reagent for Leishmania (Viannia) braziliensis indicates a dissociation between such infections in this study, as also demonstrated at the literature for the visceral form of the disease $[21,24,43]$.

Ultimately, the sample refers to an ATL endemic region located in Brazil, one of the countries with the highest endemicity levels of cutaneous leishmaniasis in the world [45] and, therefore, an important area for the implementation and evaluation of diagnostic techniques for the generation of data on the disease and its possible hosts.

\section{CONCLUSION}

Thus the present study provides information on the occurrence of ATL by Leishmania (V.) braziliensis in domestic cats; demonstrates that the methodologies employed were favorable to the use of such techniques as tools in epidemiological surveys for the diagnosis of feline tegumentary leishmaniasis; and paves the way for further studies on the subject.

\section{MANUFACTURERS \\ ${ }^{1}$ Nalgene Nunc International, Rochester, NY, USA. \\ ${ }^{2}$ Bethyl Laboratory Inc. Montogomery, TX, USA. \\ ${ }^{3}$ Sigma Chemical Co. St. Louis, MO, USA.}

Funding. This study was supported by Fundação de Amparo à Pesquisa do Estado do Rio de Janeiro (FAPERJ) - Jovem Cientista do Nosso Estado and Apoio a Grupos Emergentes de Pesquisa no Estado do Rio de Janeiro - 2013. Fabiano Borges Figueiredo holds a grant from $\mathrm{CNPq}$ for productivity in research.

Ethical approval. All procedures were approved by the Ethic Committee on the Use of Animals in Research under the number P. 0221-04 (FIOCRUZ).

Declaration of interest. The authors report no conflicts of interest. The authors alone are responsible for the content and writing of paper.

\section{REFERENCES}

1 Ayllon T., Tesouro M.A., Amusategui I., Villaescusa A., Rodriguez-Franco F. \& Sainz A. 2008. Serologic and molecular evaluation of Leishmania infantum in cats from Central Spain. Annals of the New York Academy of Sciences. 1149: 361-364.

2 Barbosa G.M., Marzochi M.C., Massard C.L., Lima G.P. \& Confort E.M. 1999. Epidemiological aspects of canine American tegumentary leishmaniasis in the Municipality of Paraty, State of Rio de Janeiro, Brazil. Cadernos de Saúde Pública. 15: 641-646.

3 Barnes J.C., Stanley O. \& Craig T.M. 1993. Diffuse cutaneous leishmaniasis in a cat. Journal of the American Veterinary Medical Association. 202: 416-418. 
4 Cardoso L., Lopes A.P., Sherry K., Schallig H. \& Solano-Gallego L. 2010. Low seroprevalence of Leishmania infantum infection in cats from northern Portugal based on DAT and ELISA. Veterinary Parasitology. 174: 37-42.

5 Cerqueira A.G.C. \& Vasconcelos A. 1922. A leishmaniose nesta capital. Boletim Sanitário. 1: 35.

6 Costa -Durão J.F., Rebelo E., Peleteiro M.C., Correia J.J. \& Simões G. 1994. Primeiro caso de leishmaniose em gato doméstico (Felis catus domesticus) detectado em Portugual (Conselho de Sesimbra). Revista Portuguesa de Ciências Veterinárias. 89: 140-144.

7 Cupolillo E., Grimaldi Jr. G. \& Momen H. 1994. A general classification of new world Leishmania using numeral zymotaxomomy. The American Journal of Tropical Medicine and Hygiene. 50: 296-311.

8 Da Silva S.M., Rabelo P.F.B., Gontijo N.F., Ribeiro R.R., Melo M.N., Ribeiro V.M. \& Michalick M.S.M. 2010. First report of infection of Lutzomyia longipalpis by Leishmania (Leishmania) infantum from a naturally infected cat of Brazil. Veterinary Parasitology. 174: 1-2.

9 De Souza A.I., Barros E.M.S., Ishikawa E., Ilha I.M.N., Marin G.R.B. \& Nunes V.L.B. 2005. Feline leishmaniasis due to Leishmania (Leishmania) amazonensis in Mato Grosso do Sul State, Brazil. Veterinary Parasitology. 128: 41-45.

10 Diakou A., Papadopoulos E. \& Lazarides K. 2009. Specific anti-Leishmania spp. antibodies in stray cats in Greece. The Journal of Feline Medicine and Surgery. 11: 728-730.

11 Dorbadam S.M., Akhlaghi L., Akhondi B., Hajjaran H., Zarei Z. \& Hadighi H. 2014. Evaluation of Leishmania infantum in cat by PCR-RFLP in an endemic region of visceral leishmaniasis in meshkin-shahr, Iran. The Journal Genes, Microbes and Immunity. 2014: 1-7.

12 Dos Santos G.P., Sanavria A., Marzochi M.C., dos Santos E.G., Silva V.L., Pacheco Rda S., Mouta-Confort E., Espindola C.B., de Souza M.B., Ponte C.S., da Conceicao N.F. \& de Andrade M.V. 2005. Prevalence of canine infection from endemic areas of American cutaneous leishmaniasis in Paracambi District, Rio de Janeiro State, between 1992 and 1993. Revista da Sociedade Brasileira de Medicina Tropical. 38: 161-166.

13 Ferreira W.A., Mayrink W., dos Mares-Guia M.L. \& Tavares C.A. 2003. Detection and characterization of Leishmania antigens from an American cutaneous leishmaniasis vaccine for diagnosis of visceral leishmaniasis. Diagnostic Microbiology and Infectious Disease. 45: 35-43.

14 Figueiredo F.B., Pereira S.A., Gremião I.D.F., Nascimento L.D., Madeira M.F. \& Schubach T.M.P. 2008. Leishmaniose tegumentar americana em felino doméstico no município do Rio de Janeiro, Brasil - Relato de caso. Clínica Veterinária. 74: 58-60.

15 Gontijo B. \& de Carvalho M.L. 2003. American cutaneous leishmaniasis. Revista da Sociedade Brasileira de Medicina Tropical. 36: 71-80.

16 Gontijo C.M., da Silva E.S., de Fuccio M.B., de Sousa M.C., Pacheco R.S., Dias E.S., Andrade Filho J.D., Brazil R.P. \& Melo M.N. 2002. Epidemiological studies of an outbreak of cutaneous leishmaniasis in the Rio Jequitinhonha Valley, Minas Gerais, Brazil. Acta Tropica. 81: 143-150.

17 Hervás J., Chacon M.D.L.F., Sanchez-Isarria M.A., Pellicer S., Carrasco L., Castillo J.A. \& Gomez-Villamandos J.C. 1999. Two cases of feline visceral and cutaneous leishmaniosis in Spain. The Journal of Feline Medicine and Surgery. 1: 101-105.

18 Kirkpatrick C.E., Farrell J.P. \& Goldschmidt M.H. 1984. Leishmania chagasi and L. donovani: experimental infections in domestic cats. Experimental Parasitology. 58: 125-131.

19 Machattie C., Mills E.A. \& Chadwick C.R. 1931. Naturally occurring oriental sore of the domestic cat in Iraq. Transactions of the Royal Society of Tropical Medicine and Hygiene. XXV: 103-107.

20 Maia C. \& Campino L. 2011. Can domestic cats be considered reservoir hosts of zoonotic leishmaniasis? Trends in Parasitology. 27 (8): 341-344.

21 Maia C., Gome J., Cristóvão J., Nunes M., Martins A., Rebêlo E. \& Campino L. 2010. Feline Leishmania infection in a canine leishmaniasis endemic region, Portugal. Veterinary Parasitology. 174: 336-340.

22 Maia C., Nunes M. \& Campino L. 2008. Importance of Cats in Zoonotic Leishmaniasis in Portugal. Vector Borne Zoonotic Disease. 8: 555-559.

23 Maroli M., Pennisi M.G., Di Muccio T., Khoury C., Gradoni L. \& Gramiccia M. 2007. Infection of sandflies by a cat naturally infected with Leishmania infantum. Veterinary Parasitology. 145: 357-360.

24 Martin-Sanchez J., Acedo C., Munoz-Perez M., Pesson B., Marchal O. \& Morillas-Marquez F. 2007. Infection by Leishmania infantum in cats: Epidemiological study in Spain. Veterinary Parasitology. 145: 267-273. 
25 Marzochi M.C.A. \& Marzochi K.B.F. 1994. Tegumentary and visceral leishmaniasis in Brazil: emerging anthropozoonosis and possibilities for their control. Cadernos de Saúde Pública. 10: 359-375.

26 Mello G.B. 1940. Verificação da infecção natural do gato (Felix domesticus) por um protozoário do genero Leishmania. Brasil Médico. 54: 180.

27 Michael S.A., Morsy T.A., El-Seoud S.F. \& Saleh M.S. 1982. Leishmaniasis antibodies in stray cats in Ismailiya Governorate, Egypt. Journal of the Egyptian Society of Parasitology. 12: 283-286.

28 Ministério da Saúde. 2010. Nota técnica conjunta da Secretaria de Vigilância em Saúde do Ministério da Saúde e da Secretaria de Estado da Saúde do Rio Grande do Sul sobre a situação da Leishmaniose Visceral na fronteira do Estado do Rio Grande do Sul com a Argentina. Available in: http://portal.saude.gov.br/portal/arquivos/pdf/nota_tec_front_br_argentina_lv_final_ses_rs.pdf [Accessed online April 2015].

29 Nascimento L.D., Passos S.R.L., Mouta-Confort E., Santiago M.A., Alves A.S., Madeira M.F., Schubach A.O. \& Marzochi M.C.A. 2009. Comparative study of amplification systems in immunoenzyme assays for the diagnosis of American tegumentary leishmaniasis. Journal of Clinical Laboratory Analysis. 23: 152-156.

30 Nasereddin A., Salant H. \& Abdeen Z. 2008. Feline leishmaniasis in Jerusalem: Serological investigation. Veterinary Parasitology. 158: 364-369.

31 Ozon C., Marty P., Pratlong F., Breton C., Blein M., Lelievre A. \& Haas P. 1998. Disseminated feline leishmaniosis due to Leishmania infantum in Southern France. Veterinary Parasitology. 75: 273-277.

32 Passos V.M., Lasmar E.B., Gontijo C.M., Fernandes O. \& Degrave W. 1996. Natural infection of a domestic cat (Felis domesticus) with Leishmania (Viannia) in the metropolitan region of Belo Horizonte, State of Minas Gerais, Brazil. Memórias do Instituto Oswaldo Cruz. 91: 19-20.

33 Poli A., Abramo F., Barsotti P., Leva S., Gramiccia M., Ludovisi A. \& Mancianti F. 2002. Feline leishmaniosis due to Leishmania infantum in Italy. Veterinary Parasitology. 106: 181-191.

34 Ribeiro F.C., Schubach A.O., Mouta-Confort E., Schubach T.M., Madeira M.F. \& Marzochi M.C.A. 2007. Use of ELISA employing Leishmania (Viannia) braziliensis and Leishmania (Leishmania) chagasi antigens for the detection of IgG and IgG1 and IgG2 subclasses in the diagnosis of American tegumentary leishmaniasis in dogs. Veterinary Parasitology. 148: 200-206.

35 Rougeron V., Catzeflis F., Hide M., De Meeus T. \& Banuls A.L. 2011. First clinical case of cutaneous leishmaniasis due to Leishmania (Viannia) braziliensis in a domestic cat from French Guiana. Veterinary Parasitology. 181: 325-328.

36 Savani E.S., de Oliveira Camargo M.C., de Carvalho M.R., Zampieri R.A., dos Santos M.G., D'Auria S.R., Shaw J.J. \& Floeter-Winter L.M. 2004. The first record in the Americas of an autochthonous case of Leishmania (Leishmania) infantum chagasi in a domestic cat (Felix catus) from Cotia County, São Paulo State, Brazil. Veterinary Parasitology. 120: 229-233.

37 Schubach T.M., Figueiredo F.B., Pereira S.A., Madeira M.F., Santos I.B., Andrade M.V., Cuzzi T., Marzochi M.C. \& Schubach A. 2004. American cutaneous leishmaniasis in two cats from Rio de Janeiro, Brazil: first report of natural infection with Leishmania (Viannia) braziliensis. Royal Society of Tropical Medicine and Hygiene. 98: 165-167.

38 Sergent E., Sergent E., Lombaard J. \& Quilichini M. 1912. La Leishmaniose à Alger. Infection simultanée d’un enfant, d'un chien et d'un chat dans la meme habitation. Bulletin de la Société de pathologie exotique. 5: 93-98.

39 Serra C.M., Leal C.A., Figueiredo F., Schubach T.M., Duarte R., Uchoa C.M., Silva R.M. \& Madeira M.F. 2003. Canine tegumentary leishmaniasis in Morada das Aguias (Serra da Tiririca), Marica, Rio de Janeiro, Brazil. Cadernos de Saúde Pública. 19: 1877-1880.

40 Shrout P.E. 1998. Measurement reliability and agreement in psychiatry. Statistical Methods in Medical Research. 7: 301-317.

41 Silva R.C.N., Ramos R.A.N., Pimentel D.S., Oliveira G.M.A., Carvalho G.A., Santana M.A., Faustino M.A.G. \& Alves L.C. 2014. Detection of antibodies against Leishmania infantum in cats (Felis catus) from the State of Pernambuco, Brazil. Revista da Sociedade Brasileira de Medicina Tropical. 47(1): 108-109.

42 Silveira T.G., Teodoro U., Lonardoni M.V., Toledo M.J., Bertolini D.A., Arraes S.M. \& Vedovello Filho D. 1996. Serologic survey of dogs in an endemic area of tegumentary leishmaniasis in Parana State, southern Brazil. Cadernos de Saúde Pública. 12: 89-93.

43 Solano-Gallego L., Rodríguez-Cortés A., Iniesta L., Quintana J., Pastor J., Espada Y., Portús M. \& Alberola J. 2007. Cross-sectional serosurvey of feline leishmaniasis in ecoregions around the Northwestern Mediterranean. The American Journal of Tropical Medicine and Hygiene. 76: 676-680. 
F.B. Figueiredo, L.D. Nascimento, T.C.B. Vasconcelos, et al. 2016. Serological Diagnosis of Feline Tegumentary Leishmaniasis by Indirect Immunofluorescence... Acta Scientiae Veterinariae. 44: 1422.

44 Torres F.D., Mattos L.S., Brito F.L.C., Figueiredo L.A. \& Faustino M.A.G. 2006. Leishmaniose felina: revisão de literatura. Clínica Veterinária (março/abril): 32-40.

45 World Health Organization (WHO). 2012. Status of endemicity of cutaneous leishmaniasis, worldwide, 2012. Available in: http://gamapserver.who.int/mapLibrary/Files/Maps/Leishmaniasis_CL_2013.png?ua=1 [Accessed online April 2015].

46 Vita S., Santori D., Aguzzi I., Petrotta E. \& Luciani A. 2005. Feline leishmaniasis and ehrlichiosis: serological investigation in Abruzzo region. Veterinary Research Communications. 29: 319-321. 